Second, dealing predominantly with male mosquitoes need not be a great handicap. A specialist in mosquito ecology can obtain the dispersal pattern of females of a species of mosquito by extrapolating the dispersal data of males.

Your leader gives an erroneous impression that we were the only two "to level accusations of BW." Other witnesses who appeared before the Parliamentary Public Accounts Committee (PAC) belonged to the health and defence ministeries. Of course they will not accuse themselves. But if you had carefully read the PAC report you would have noticed statements made by health officials admitting that both the GCMU project and the Jodhpur project (another WHO venture about which your leader is silent) could provide data useful in BW.

You may be "revolted" by the thought that the US government was using an intermediate organisation (WHO) to learn how to infect the Indians with yellow fever. Do you know that the USA was alleged to have used an FAO expert (an Indian) in 1970 to sabotage Cuban sugar cane research?

Do you know that a US expert working at the Indian Agricultural Research Institute (IARI) here was caught at the India-Pakistan border in 1971 with his luggage containing wheat germ plasm collected by the IARI?

It was unfortunate that articles criticising the GCMU and other projects were interpreted to be anti-American. This was never intended. The bird migration studies supported by the GCMU and the US army at the Bombay Natural History Society exemplified the casual attitude of some to foreign funded research. But many other countries have set up collaborative projects covering agriculture, livestock and the continental shelf.

Although we journalists appeared before the PAC late in the day, the same questions put to us were also put to official witnesses and they were given every opportunity to give answers.

You seem to regard the WHO pulling out from an "important" research project as bad. Bad for whom? Not for India which needs to tackle malaria now and not 40 years hence when genetic control may become viable scientifically-but not economically.

As far as filariasis is concerned, an expert report to the Indian Council of Medical Research had clearly said in 1971 that the strategy is not elimination of the vector Culex fatigansbut protection with drugs of the vulnerable population below the age of 21 in the endemic regions.

Chikungunya and dengue are not major health problems in India (as they were made out to be during the GCMU controversy) and control of Aedes aegypti has the least priority. That dengue gives cross protection against yellow fever is so strongly established (Theiler, Max, Arthropod borne diseases in vertebrates; 1973) that grand projects to eradicate Aedes aegypti-even though foreign-financed and with WHO sanction-can be only anything but scientific.

Arguments that yellow fever did not strike after elimination of Aedes aegypti from Poona in 1953 are too weak to disprove Max Theiler's conclusion that a person immune to dengue is automatically immune to yellow fever. Such arguments are too childish to be taken seriously by the health department of any country. Yellow fever did not come to Poona perhaps because other vectors of yellow fever were also not present, or there were missing links in the epidemiological chain.

If the closing of the GCMU causes concern to British scientists they may well restart the project around London. It is better that sophisticated technologies (genetic manipulation is one) are first tried and developed in advanced countries before they are recommended to developing countries.

Your worries that India will find few opportunities to collaborate with the rest of the scientific world are unwarranted. Right now India collaborates with some 40 countries. Almost every month some science agreement or other is signed. Under such circumstances it is only natural for the PAC to recommend that foreign research in certain areas like weather modification, and oceanography should be scrutinised from the security angle.

The PAC has not banned foreign collaboration in science but has asked for the closer participation of Indian scientists who are at present given subordinate roles and not decision-making or project-management roles in foreign-funded research. The PAC has also called for thorough scrutiny by a governmental clearing body as you yourself have admitted that "almost everything has its military aspect."

We would like to ask, for instance, if the British government will allow a team of foreign scientists to go about surveying Britain's continental shelf, causing artificial earthquakes in "search of minerals", or releasing new strains of pigeons in Trafalgar Square?

$$
\begin{aligned}
& \text { C. Raghavan } \\
& \text { K. S. Jayaraman }
\end{aligned}
$$

Press Trust of India Ltd.

New Delhi, India

\section{Unwelcome error}

SrR,- Something went a little wrong, I am afraid, in the box headed "Wellcome Foundation" in your guide "How Britain Runs its Science" (August 28).

The Wellcome Foundation Limited is the parent company of a British based pharmaceutical group trading as Burroughs Wellcome, Coopers and Calmic around the worid. Its chairman is $\mathrm{Mr}$ A. A. Gray. Like any other pharmaceutical group it spends money on its own research and development.

All its shares are owned by a registered charity, The Wellcome Trust, which under the Will of Sir Henry Wellcome, who died in 1936, applies all moneys it receives, as sole shareholder, to the support of medical and allied research in universities and hospitals around the world. The Director of The Wellcome Trust is Dr P. O. Williams, and I think it is the Trust rather than the foundation that should have been featured in your guide.

The figure you gave for research grants is actually the foundation's expenditure on research and development for the year ended August 31, 1974.

Yours faithfully,
BASIL SAUNDERS
The Wellcome Foundation Ltd,
London, UK

ED-Indeed the Wellcome Trust, rather than the foundation, ought to have been featured in our guide. Before anyone starts applying for a slice of the $£ 11.5$ million which the foundation allocated to research and development last year, we had better point out that the trust's spending on research assistance (1972-74) was $£ 1,133,463$.

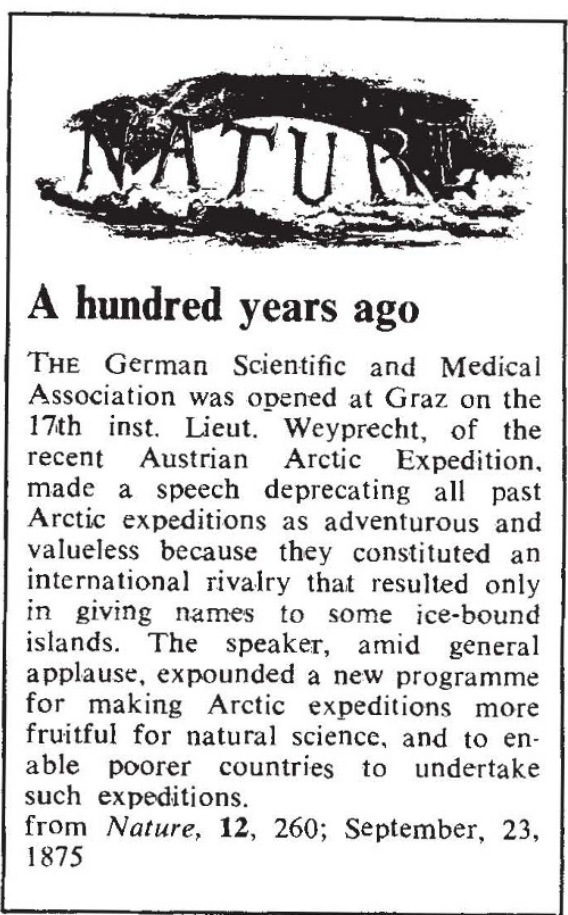

